\title{
Applying the Criminal Narrative Experience Framework to Missing Children
}

\author{
Daniel Hunt ${ }^{1}$ \\ ${ }^{1}$ School of Human and Health Sciences, Department of Psychology, University of \\ Huddersfield, HD1 3DH
}

\begin{abstract}
Author Notes
Correspondence concerning this article should be addressed to Dr Daniel Hunt, School of Human and Health Sciences, Department of Psychology, Edith Key Building, University of Huddersfield, HD1 3DH, United Kingdom. Email: d.hunt2@ hud.ac.uk
\end{abstract}

\section{Data Availability Statement}

The data that support the findings of this study are not publicly available due to containing information that could compromise the privacy of participants.

\section{Funding Statement}

This work did not receive any funding and was supported by the University of Huddersfield.

\section{Conflict of Interest Disclosure Statement}

No potential conflict of interest was reported by the author.

\section{Ethics Approval Statement}

The study was ethically approved by the School Research Ethics and Integrity Committee at the University of Huddersfield. 


\begin{abstract}
Over 320,000 missing persons are estimated to go missing annually in the UK due to a variety of intentional and unintentional factors. This article aims to investigate whether the criminal narrative experience framework can be applied to missing persons to acquire a deeper insight into the psychological differences between missing children. Sixty-one previously missing persons completed a missing experience survey, narrative roles questionnaire, and emotions questionnaire. Data were content analysed and subjected to a non-metric, multi-dimensional scaling procedure in the form of smallest space analysis. The results identified four distinct behavioural themes: Depressed Throwaway Victim, Distressed Pushaway Revenger, Calm Runaway Professional, and Elated Fallaway Hero. Following a stringent criterion, $88.50 \%$ of the sample could be differentiated into one dominant behavioural theme with the remaining $11.50 \%$ identified as a hybrid theme. Due to the exploratory nature of the study, additional exploration of the applicability of the framework is required.
\end{abstract}

Keywords: Criminal Narratives; Missing Children; Missing Children Narrative Experience Framework; Missing Persons; Narrative Experience 


\section{Applying the Criminal Narrative Experience Framework to Missing Children}

In the UK, it is estimated that over 320,000 missing person incidents are reported to the police annually which is equivalent to one report every 90 seconds (Missing People, 2018; National Crime Agency [NCA], 2020). Approximately $62 \%$ of these incidents relate to missing children (NCA, 2020). The factors associated with going and being missing are wide-ranging and complex and may be due to numerous intentional or unintentional factors. For instance, a child may go missing due to mental health difficulties, suicidal ideations, being a victim of child sexual exploitation or county lines, becoming lost in travel, or following family or school related difficulties (Alys, Massey \& Tong, 2013; Biehal, Mitchell \& Wade, 2003; Hayden \& Shalev-Greene, 2016; Hunt, Ioannou \& Synnott, 2019, 2020; James, Anderson \& Putt, 2008). Although research focus on missing persons has increased in recent years, the deeper psychological understanding of the circumstances and motivations behind why individuals go missing and the decisions made whilst missing remain undeveloped (Biehal et al., 2003; Hirschel \& Lab, 1988). Therefore, this article aims to investigate whether the development and utilisation of a theoretical framework of missing children via the narrative experience framework could help to assist police investigations through improved decision-making, risk assessments, prioritised search locations, and operational responses.

The exploration of missing person behaviours is not a novel approach with numerous typological research present which aims to acquire the underlying behavioural differences between missing persons. For instance, Payne (as cited in Payne, 1995) differentiated missing children behaviours derived from the literature into one of five typologies that identified driving forces that influenced the children into going missing. The pushaway identified children who believe that they are forced into going missing because of the behaviours of those around them, whilst the takeaways went missing involuntarily through stranger or custodial 
abductions (Payne, 1995). Runaways reflected children who voluntarily went missing through impulsive decisions due to immediate social stressors, whilst fallaways were children who had simply lost contact with others (Payne, 1995). Finally, throwaways identified children who went missing due to being thrown out of their current residence (Payne, 1995). Whilst this typology does help to identify some of the factors that influenced the child to go missing, it fails to explore the psychological differences between these individuals that can drive subsequent decision-making during the missing period. Moreover, the data utilised in this typological model derived from research literature and thus requires an improved and updated empirical approach to fully explore missing children behaviours in the modern era and from their own perspective as opposed to secondary data analysis.

Building on this work further, Henderson, Henderson, and Kiernan (2000) developed an empirically driven typology that utilised over 500 Australian police missing persons reports, consultations with missing people organisations, and 270 interviews with the family and friends of missing persons. Three categories of missing persons were identified that reflect individuals who had gone missing unintentionally via accidents or miscommunications, intentionally as an act of rebellion or to gain independence, and those who sought to escape undesirable consequences (Henderson et al., 2000). Similarly, Bonny, Almond and Woolnough (2016) analysed 362 missing adult reports within Scotland to also identify three categories. The first, dysfunctional, identified vulnerable adults who had gone missing due to mental health difficulties or ongoing addiction problems, whilst the second grouping, escape, identified adults who go missing to overcome current life stressors (Bonny et al., 2016). The final category, unintentional, identified adults who had simply lost contact with other individuals around them (Bonny et al., 2016). Therefore, whilst these typologies begin to identify some of the factors associated with going missing, they focus solely on the circumstantial causes of the missing period for adults and thus fail to explore the deeper underlying psychological 
influences between those who go missing which drives these behaviours and subsequent decision-making.

\section{Criminal Narrative Theory}

Narrative theories propose that every individual develops their own life story, or narrative, as a way of understanding the world around them whereby each individual encompasses a dominant role within their own life narrative alongside the plot or setting of their lived world (McAdams, 1988). These narrative theories originate from the work of Frye's (1957) "Theory of Mythoi" which has the notion that every individual story can be differentiated into one of four dominant behavioural themes which represent a unique reflection of the individual's own lived reality. McAdams $(1988,2001)$ further proposed that these unique life stories revolve around two primary dimensions of intimacy and agency. Intimacy reflects the understanding and development of close personal relationships whilst agency reflects the sense of power and action (McAdams, 2001). Thus, life narratives are created through a combination of the individual's unique experience, mental state, and events experienced that allows the individual to identify and understand their perceived sense of self within their own social ecology (Bruner, 1990). The exploration of life narratives in general has been widely utilised within the general population (McAdams, 1988), although continued development of these theories have started to explore life narratives of offenders to develop a greater understanding of the underlying psychological motivations of criminal behaviour.

Canter (1994) was the first to propose that utilising narrative approaches to advance our understanding of how characteristic actions and roles that individuals assign themselves may give rise to interpret how individuals give meaning to their actions. For example, Canter, Kaouri and Ioannou (2003) analysed 161 interviews with offenders from a variety of criminal contexts, identifying supportive evidence that four distinct narratives could differentiate the 
actions and roles that the offenders had assigned themselves. The first narrative, professional, identified task-focused individuals whilst the second narrative, victim, reflected those who feel victimised and attributes their actions to external factors (Canter et al., 2003). The third narrative, revenger, reflected those who justified their actions as a way to right the wrongs they believe have been placed against them whilst the final narrative, hero, identified those who seek to overcome current obstacles in their life such as internalised difficulties (Canter et al., 2003). Thus, Canter et al. (2003) were able to identify opposing psychological differences between individual offenders which subsequently influenced their criminal motivations and behaviours.

The notion of the four structured narrative themes has been supported by numerous research studies across a variety of contexts and populations that includes arsonists (Canter \& Fritzon, 1998), terrorism (Canter, Sarangi \& Youngs, 2014), school shootings (Ioannou, Hammond \& Simpson, 2015), rioters (Willmott \& Ioannou, 2017), psychopathic and personality disordered offenders (Goodlad, Ioannou \& Hunter, 2019), burglary (Yokoto \& Canter, 2004), contract killing (Yaneva, Ioannou, Hammond \& Synnott, 2018), sexual assaults (Almond \& Canter, 2007), homicide (Santtilla, Hakkanen, Canter \& Elfgren, 2003), online and offline grooming (Ioannou, Synnott, Reynolds \& Pearson, 2018), stalking (Canter \& Ioannou, 2004), and offenders in general for both adult offenders (Ioannou, Canter, Youngs \& Synnott, 2015) and young offenders (Ioannou, Synnott, Lowe \& Tzani-Pepelasi, 2018).

Evidently, these research findings have utilised data from criminal contexts as opposed to missing person cases which may not always involve a crime (James et al., 2008). However, as Canter and Youngs (2012) argue, the adoption of the narrative approach identifies these offenders as being active agents in their crimes as opposed to playing a passive role which can be common with other theoretical perspectives on behaviour. Therefore, the utilisation of a criminal narrative approach allows a deeper interpretation of active behavioural explanations 
(Presser, 2009), and may therefore build upon our current understanding of missing person behaviours by exploring the underlying psychological roles which are assigned by the missing individuals themselves in their own life narratives.

\section{The Emotional Experience}

In addition to understanding the underlying psychological and behavioural actions of criminal behaviour, there are suggestions that there is also a need to explore the emotional experience of actions which can further contribute to the decisions made by the individual (Youngs \& Canter, 2012). Russell (1980) originally identified two primary dimensions to mood experienced by individuals in the form of arousal and pleasantness before building on this further with a framework termed the circumplex of emotions (Russell, 1997). The circumplex has the notion that emotions can be presented in a circular order based on the dimensional axis of arousal/non-arousal and pleasure/displeasure and thus presents four distinct groupings of emotions: calm, depression, elation, and distress (Russell, 1997). As Katz (1988) suggests, the affective states experienced by the individual at that particular time of their behaviour can encourage and influence the type of behaviour exhibited such as the experience of anger resulting in aggressive criminal behaviour (Ioannou, Canter \& Youngs, 2016).

Initially proposed by Ioannou (2006) and developed further by Ioannou et al. (2016), this emotional experience was adopted into the criminal narrative framework to reflect the underlying psychological, behavioural, motivational, and emotional experience contained within an individual's life narrative. Incorporating the works of Frye (1957) and Russell (1997), it was proposed that the framework would comprise of four distinct regions which reflect the criminal narrative roles (Canter et al., 2003) alongside the emotional experience of the individuals during their offending behaviour. The criminal narrative experience framework thus identified four distinct themes of the calm professional, elated hero, distressed revenger, 
and depressed victim. Each of these themes provides a unique exploration of the underlying psychological, emotional, and behavioural actions associated with how one identifies their role in life and how they understand and experience the world around them (Ioannou, Synnott, Lowe \& Tzani-Pepelasi, 2018).

\section{Purpose of the Present Study}

The research literature presented thus far highlights the importance of the utilisation of a narrative approach to identify the underlying psychological, emotional, and behavioural actions exhibited by individuals although the majority of research studies exploring the criminal narrative experience framework have employed samples of offenders. Nevertheless, as the framework provides a unique exploration of an individual's underlying emotional, behavioural, and psychological actions, it could be argued therefore to be applicable to samples beyond offenders. The factors associated with going and being missing are wide-ranging and complex due to numerous intentional or unintentional factors that may be involved (Biehal et al., 2003). Therefore, it would be advantageous to apply the criminal narrative experience framework to missing persons to further explore the underlying behavioural and psychological actions exhibited which may subsequently identify unique behavioural differences on the decisions made by these individuals whilst missing. Therefore, the present study sought to investigate whether the criminal narrative experience framework can be applied to missing children to acquire a deeper insight into the emotional, behavioural, and psychological differences of missing children. It is hypothesised that whilst the narrative roles will be theoretically similar to previous findings discussed, they will differ pragmatically given the specific nature of the sample on missing persons as opposed to criminal offenders. This study therefore presents a novel exploration into the development of a missing children narrative 
framework which is based upon the individual's own lived reality and how the role that they view themselves as playing within their interpretation of the world around them.

\section{Method}

\section{Sample}

A total of 84 participants completed the online study through convenience and snowball sampling methods, although 23 participants were removed due to partial completion of the study. Therefore, the final sample consists of 61 participants (43 females; $M_{\mathrm{age}}=21.17, S D=$ 5.54). All research participants were recruited voluntarily using the researcher's social media sites initially or through an online experimental recruitment system for the psychology department at the university. Individuals who observed the request for research participants via the researcher's social media sites were requested to share this request with their own social media followers to reach as many individuals who fulfil the inclusion criteria as possible. The request for research participants sought individuals who are currently 18 years of age or above and who had previously gone missing when they were a child. Individuals who had gone missing only as an adult were excluded from the study. Participants who took part in the study via the social media links did not receive any incentives for taking part whilst participants who took part in the study via the university research system had received 0.5 credits for taking part as part of the requirements included within their psychology courses. Participants were able to take part in the research study in any location and during any time that they found most comfortable and had accessed the study using the Qualtrics software. Sample demographics are presented in table 1.

[INSERT TABLE 1 HERE] 


\section{Materials}

All participants had completed a single online experimental study which comprised of the following.

\section{Missing Person Experience Survey}

The missing person experience survey items were developed by the researcher for this study based upon common behaviours and investigative details associated with missing persons to explore the participants' missing experience during their missing episode as a child. The majority of these questions presented predefined options for participants to select the most appropriate response to the question and were coded as being $0=$ absent or $1=$ present. These questions included the factors associated with the motivation for deciding to go missing, whether any preparations were made before going missing, items that were taken or deliberately left behind, the locations visited during the missing episode, the types of harm experienced, activities performed during the missing episode, and the outcome of the missing episode. A small number of questions within the survey allowed the participants to input their responses freely such as the number of times they had gone missing, the age they were when they had first gone missing, the reasons behind the decisions for leaving items behind, the estimated length of time that they had remained missing.

\section{Narrative Roles Questionnaire}

The criminal narrative roles questionnaire (Canter et al., 2009) is a 36-item inventory designed to reflect the narrative role that offenders see themselves enacting when committing their crimes. The questionnaire comprises of the four themes which correlate to the four narrative roles of the victim, the revenger, the hero, and the professional which were developed 
through studies utilising qualitative interviews with offenders (Canter et al., 2003, 2009). A 5point Likert scale ranging from 1 (not at all) to 5 (very much) was used whereby participants were required to indicate the extent to which each of the statements described what it was like during their missing episode. The questionnaire instructions were worded slightly differently to reflect their missing experiences as opposed to the original questionnaire instructions which reflect the individuals' criminal experiences. The original questionnaire has been utilised across numerous types of offenders and types of crimes committed finding consistent results (Ioannou, Canter \& Youngs, 2017; Ioannou et al., 2018; Spruin, Canter, Youngs \& Coulston, 2014).

\section{The Emotional Experience Questionnaire}

The emotional experience questionnaire comprises of 26 statements which are hypothesised to reflect the range of emotions that may be felt by the offender whilst committing their crimes. These statements were developed by Canter and Ioannou (2004) and incorporates the full gamut of Russell's (1997) circumplex. Each statement was rated on a 5-point Likert scale ranging from 1 (not at all) to 5 (very much) in which participants were required to indicate the extent to which each of the statements described their emotional reactions during their missing episode. As with the criminal narrative roles questionnaire, the emotional experience questionnaire instructions were marginally modified to reflect the participants' missing experiences as opposed to the original instructions which reflect the participants' criminal experiences.

\section{Demographic Survey}

The demographic survey section requested participants to specify their current age, gender, the highest level of education completed, marital status, sexual identity, medical 
background information which have been formally diagnosed by a medical profession, and medical background information which the participant believes they may have but has not been formally diagnosed by a medical profession.

\section{Procedure}

The present study utilised the Qualtrics Inc. survey software (www.Qualtrics.com). Participants who had observed the social media postings or the study details within the university's experimental portal were requested to select the web link if they wished to participate in the study. Participants were then presented with an information sheet for the study which outlined the experimental study's purpose, data collection proceedings, secure storage of the research data, ethical considerations, and the contact details of the researcher. Participants were then required to read and sign the consent form. Once consented, participants were presented with the missing experience survey whereby they were asked to provide as many details as possible relating to their experience for their most recent missing period.

After completing the missing experience survey, participants were directed to the narrative roles questionnaire which contained a series of 35 statements describing some of the underlying motivations and behaviours that may or may not have been relevant to the participants' own missing experience. Participants were then presented with the emotions questionnaire which comprises of 26 statements which may or may not have reflected the participants' emotional responses during their missing period. Once all survey items had been completed, the participants were presented with the demographic survey followed by a full debrief information sheet and to thank the participants for taking part.

\section{Analysis}


The data generated from the questionnaire responses were analysed via smallest space analysis ([SSA]; Lingoes, 1973). SSA is a nonmetric multidimensional scaling procedure with the assumption that the underlying system of behaviour will be most readily appreciated if the relationship between one variable with every other variable is examined. SSA characterises the co-occurrence of the variables, namely emotions and narrative roles in the present study, as distances in a geometric space. The SSA programme computes the association coefficients between each variable with every other variable. It is, therefore, the result of these coefficients that are used to create a spatial representation of the items with points in the space representing the variables. In essence, the closer together any two points in the geometric space are to each other, the higher their associations are with each other. Likewise, the farther away from each other any two points in the geometric space are to each other, the lower their associations are with each other.

Multidimensional scaling models have been found to be highly productive across studies from intelligence to a variety of criminal actions (e.g. Canter \& Fritzon, 1998; Canter \& Heritage, 1990; Guttman, 1954; Ioannou, Canter \& Youngs, 2017; Ioannou et al., 2018; Salfati, 2000). The power of SSA-I originates in its representation of the rank order of cooccurrence as rank orders of the distances in the geometric space. To test hypotheses, SSA configurations are visually examined to establish patterns of relationships between the variables to identify potential thematic structures. The emotions and narrative roles are therefore hypothesised to be more likely to co-occur than those that indicate different underlying themes. As such, it is hypothesised that these similarly themed narrative roles and emotions will be found in contiguous locations. In essence, the similarly co-occurring variables will cluster in the same regions of the geometric plot. The hypothesis can therefore be tested by visually examining the SSA configuration. 
The coefficient of alienation (Borg \& Lingoes, 1987) signifies how well the spatial representation fits the co-occurrences represented in the matrix. A smaller coefficient of alienation thus indicates a better fit. However, as Borg and Lingoes (1987) emphasise, there is no simple answer to how good or bad the fit is as this depends upon the combination of the number of variables present, the logical strength of the interpretation framework, and the amount of error in the data. Thus, the SSA was utilised to explore the co-occurrence of narrative roles and emotions for previously missing persons and allowed for the testing of the hypothesis that they will be differentiated into underlying themes. Pearson's coefficient was utilised for the current study analysis as the data analysed derived from the Narrative Roles questionnaire and the Emotional Experience questionnaire which are scored on a Likert scale ranging from 1 (not at all) to 5 (very much). The variables and coding used to explore the missing persons' behaviours and emotions as well as the frequencies of participant responses can be seen within the supplementary materials.

\section{Results}

\section{Descriptive Statistics}

Initial descriptive analysis of the participants' missing experiences found that the average number of times they had gone missing was $2.05(S D=1.61)$ times for an average of $29.29(S D=43.61)$ hours. Participants had indicated that on average, they had gone missing for the first time when they were $13.30(S D=3.22)$ years old. The descriptive analysis also found that $47.50 \%(n=29)$ had made some form of preparation to go missing prior to their missing episode, with planning their route or places to go $(41.38 \%, n=12)$ the most common form of preparation made. This was followed by packing items deemed to be essential $(34.48 \%$, 
$n=10)$, leaving a note $(20.69 \%, n=6)$, and buying a transportation ticket in advance $(3.45 \%$, $n=1)$. The factors associated with deciding to go missing can be seen in table 2 .

\section{[INSERT TABLE 2 HERE]}

In relation to harm experienced, descriptive analyses found that $52.50 \%(n=32)$ had experienced some form of harm during their missing episode. Harm experienced whilst missing included self-harm $(14.80 \%, n=9)$, accidental harm $(14.80 \%, n=9)$, physical harm $(13.10 \%$, $n=8)$, sexual harm $(6.60 \%, n=4)$, verbal harm $(3.30 \%, n=2)$, or other form of harm $(4.90 \%$, $n=3)$. In addition, 34 participants $(55.70 \%)$ had indicated at least one of the following activities had been performed during the missing episode. These activities include sleeping rough $(24.60 \%, n=15)$, shoplifting $(16.40 \%, n=10)$, begging $(11.50 \%, n=7)$, burglary $(4.90 \%, n=$ 3), having sex for goods $(4.90 \%, n=3)$, having sex for money $(3.30 \%, n=2)$, thievery $(3.30 \%$, $n=2)$, selling drugs $(3.30 \%, n=2)$, and being physically violent to another $(1.60 \%, n=1)$. Locations visited whilst missing and the outcome of the missing episode can be found in table 3.

[INSERT TABLE 3 HERE]

\section{Smallest Space Analysis}

Figure 1 demonstrates the distribution of the 62 statements derived from the criminal narrative roles questionnaire and the emotional experience questionnaire. The two-dimensional SSA has a Guttman-Lingoes coefficient of alienation of 0.198 in 12 iterations whilst the threedimensional SSA has a Guttman-Lingoes coefficient of alienation of 0.147 in 26 iterations. Therefore, the three-dimensional SSA shows a better fit between the Pearson's coefficients of 
the narrative roles and emotion variables and their geometric distribution within the configuration. The study aimed to examine the extent to which previously missing children behaviours could be classified into distinct themes using the narrative role model. The first examination of the SSA plot relating to the emotion variables demonstrates a two-part division between negatively experienced emotions presented on the left-hand side of the plot and positively experienced emotions presented on the right-hand side of the plot. This division is illustrated in Figure 1 as displeasure and pleasure. The emotions sit within two extremes which range from a sense of despair on the far left-hand side of the plot to a sense of joyfulness on the far right-hand side of the plot.

In order to determine the reliability coefficient for the elements that defined each region for the four behavioural and emotional themes identified, Cronbach's $\alpha$ was calculated. The depressed throwaway victim with 12 items had an $\alpha$ coefficient of .932 , the distressed pushaway revenger with 16 items had an $\alpha$ coefficient of .752, the calm runaway professional with 20 items had an $\alpha$ coefficient of .874, and the elated fallaway hero with 14 items had an $\alpha$ coefficient of .946. Thus, the $\alpha$ coefficients indicate a high degree of association between the variables within each of the four behavioural and emotional themes identified.

[INSERT FIGURE 1 HERE]

\section{Themes of the Missing Children Narrative Experience}

The test of the hypothesis is that the emotions and narrative roles experienced whilst missing should form visible patterns of relationships which can be identified in the SSA plot as clusters of frequently co-occurring variables which result in the formation of distinct and identifiable regions. The additional examination of the SSA plot revealed that the narrative roles and emotional experiences of previously missing persons can be differentiated into four 
dominant behavioural themes. Thus, with the incorporation of Ioannou's (2017) criminal narrative experience framework and Payne's (1992, in Payne, 1995) typology of missing children, the four thematic behavioural themes can be identified as the depressed throwaway victim, the distressed pushaway revenger, the calm runaway professional, and the elated fallaway hero.

\section{Depressed Throwaway Victim}

This region of the plot consists of the depressed theme of emotions and the victim theme of roles. The elements and subsequent code numbers included within the SSA plot that can be identified as the depressed throwaway victim are as follows: 17. Helpless; 46. Upset; 47. Worried; 48. Angry; 49. Scared; 50. Confused; 51. Miserable; 52. Sad; 53. Depressed; 54. Pointless; 55. Unhappy; and 56. Lonely. Within this behavioural theme, this type of missing person can be described as an individual who feels rejected and thus the act of going missing aims to escape these internal difficulties with the belief that there is no other way to overcome these challenges.

\section{Distressed Pushaway Revenger}

This region of the plot consists of the distressed theme of emotions and the revenger theme of roles. The elements that can be identified as the distressed pushaway revenger are as follows: 2. Had to; 7. Nothing Mattered; 13. Only Thing; 15. Routine; 18. Only Choice; 19. Victim; 20. Confused Happened; 21. Recognition; 22. Get Over it; 23. Didn't Care; 26. Couldn't Stop; 27. No Part; 32. Think of Doing; 44. Annoyed; 45. Irritated; 57. Thoughtful. Within this behavioural theme, this type of missing person can be described as an irritated and annoyed individual who feels the act of going missing was caused by others around them. The distressed pushaway revenger theme demonstrates that the act of going missing therefore aims 
to allow the individual to regain a sense of recognition from those they believe forced them to go missing and that going missing was the only thing they could think of doing to achieve this sense of recognition.

\section{Calm Runaway Professional}

This region of the plot consists of the calm theme of emotions and the professional theme of roles. The elements that can be identified as the calm runaway professional are as follows: 1. Professional; 4. Right; 8. Control; 10. Acting Revenge; 11. Doing Job; 12. Knew Doing; 14. Mission; 16. Power; 24. Fate; 25. Plan; 28. Manly Thing; 29. Usual; 30. Trying Revenge; 33. Nothing Special; 34. Getting Own Back; 35. Taking Risk; 36. Always Knew; 40. Pleased; 42. Courageous; 43. Felt Manly. Within this behavioural theme, this type of missing person can be described as an individual who is calm and confident in their approach to going and being missing. This type of individual does not contemplate the act of going missing as anything special and considers this act as a type of mission or job which is demonstrated by the element of planning and understanding that they knew what they were doing. The motivational aim of the calm runaway is to regain a sense of power and control.

\section{Elated Fallaway Hero}

This region of the plot consists of the elation theme of emotions and the hero theme of roles. The elements that can be identified as the elated fallaway hero are as follows: 3 . Fun; 5 . Interesting; 6. Adventure; 9. Exciting; 31. Being on an Adventure; 37. Exhilarated; 38. Delighted; 39. Excited; 41. Enthusiastic; 58. Calm; 59. Contented; 60. Relaxed; 61. Confident; 62. Safe. Within this behavioural theme, this type of missing person can be described as an individual who sees the act of going and being missing as a brave and exciting adventure. This individual also demonstrates a sense of pleasure and confidence in being and going missing. 


\section{Testing the Framework}

The smallest space analysis demonstrates that the emotions and narrative roles experienced whilst missing can be classified into four distinct themes. However, the SSA model does not classify each individual missing person. To test the appropriateness of the thematic regions further, each of the 61 cases were individually examined to identify whether they could be assigned to a particular theme based on the individuals' missing experience. As each of the four themes contains an unequal number of variables, each case was analysed to identify an overall percentage score for each region which reflects the scores of individual variables that are conceptually linked to each individual theme.

A case was classified as belonging to a particular behavioural theme when their score for the most dominant theme was at least $10 \%$ or above the scores derived for the other three behavioural themes. As each of the items within behavioural themes derives from a Likertscale, each individual case had scores out of a possible $100 \%$ which is a similar classification method to the one used in previous studies (Ioannou et al., 2016; Ioannou et al., 2018). In contrast, an individual case was identified as being a hybrid if it contains an identical score for two themes. Unclassified cases were therefore individual cases which had no identifiable dominant theme due to having similar scores across all of the themes.

Based upon this criterion, $88.50 \%(n=54)$ could be identified as being a pure type with $11.50 \%(n=7)$ being identified as a hybrid. The most frequent pure type identified was that of the Depressed Throwaway Victim which represented 67.20\% $(n=41)$ of the cases. The Elated Fallaway Hero theme was found to be the second most frequent pure type with $13.10 \%(n=8)$ of cases classified, followed by Calm Runaway Professional with 4.90\% $(n=3)$ of cases and Distressed Pushaway Revenger with 3.30\% $(n=2)$ of cases. This classification method also identified $11.50 \%(n=7)$ as hybrid cases which consisted of a Depressed Throwaway Victim 
/ Distressed Pushaway Revenger hybrid ( $n=3)$, Elated Fallaway Hero / Distressed Pushaway Revenger hybrid ( $n=2)$, Distressed Pushaway Revenger / Calm Runaway Professional hybrid $(n=1)$, and Elated Fallaway Hero / Calm Runaway Professional hybrid $(n=1)$.

\section{Discussion}

Narrative theories propose that every individual develops their own life story, or narrative, as a way of understanding the world. Thus, the current study sought to gain a deeper insight into the missing persons experience via the application of the narrative role model to explore the missing persons' underlying psychological motivations and behaviour for going and being missing. It was hypothesised that the narrative roles will be theoretically similar to previous findings but would differ pragmatically due to the nature of the sample on missing persons as opposed to criminal offenders. Results of the analysis show that $88.50 \%$ of the missing persons could be differentiated into one of four distinct behavioural themes of either the Depressed Throwaway Victim, Elated Fallaway Hero, Calm Runaway Professional, or Distressed Pushaway Revenger. The remaining $11.50 \%$ were identified as being a hybrid between two distinct behavioural themes. Therefore, this provides strong evidence that missing persons have a predominant narrative.

\section{The Missing Children Narrative Experience}

The present study demonstrates the importance of exploring, and the applicability of, Canter et al.'s (2003) criminal narrative roles model and Ioannou et al.'s (2016) criminal narrative experience framework to missing persons. Life narratives are the combination of an individual's unique experiences, events experienced, and their mental state which allows them to identify and understand their perceived sense of self within their own social ecology (Bruner, 
1990). The findings of the present study identified four narrative themes of missing persons which can be combined with Payne's (1992 in Payne, 1995) missing children typology to provide a deeper psychological and behavioural understanding of missing person behaviours and motives for going missing. For instance, individuals who adopt a depressed throwaway victim role feel rejected and go missing to escape internal difficulties whilst those who adopt the distressed pushaway revenger role go missing to regain a sense of recognition from those who they believe have forced them to go missing. In contrast, missing persons who adopt the elated fallaway hero role feel a sense of excitement and pleasure when going missing whilst those who adopt the calm runaway professional role considers the act of going missing as a type of mission with evidence of prior planning.

The majority of missing persons within the sample were found to adopt the Depressed Throwaway Victim role (67.20\%). The throwaways relate to those who feel rejected and endure ongoing individualistic difficulties. Thus, the main goal of the missing throwaway is to escape these problems that is demonstrated by the act of going missing to voice their unhappiness to those 'left behind'. The throwaway therefore associates with the victim role whereby the individual feels victimised and does not attribute their actions as their own responsibility (Canter et al., 2003). The variables 'upset', 'scared' and 'lonely' thus supports the concept of victimisation due to externalised difficulties.

The second-most narrative role adoption was the Elated Fallaway Hero role (13.10\%). Individuals who adopt this role were found to have 'fallen away' from their social networks and demonstrate low levels of potency and high levels of intimacy. The current findings support this notion as missing persons expressed a range of highly emotive considerations for going missing such as being excited, going on an adventure, and being delighted about going and being missing. Thus, the fallaways narrative parallels the hero role wherein the intention is to overcome challenging obstacles (Canter et al., 2003). 
The Calm Runaway Professional role was the third most adopted role (4.90\%). The runaway demonstrates high levels of potency and thus the act of going missing is a demonstration of unhappiness. The runaway is therefore associated with the professional narrative role (Canter et al., 2003) whereby the underlying motivational aim of the individual is to regain a sense of power and control. Finally, the Distressed Pushaway Revenger was the least adopted role $(3.30 \%)$ and reflects those who feel forced into going missing due to the behaviours others and thus do not seek personal desires, but right the wrongs against them (Canter et al., 2003).

\section{Theoretical and Practical Implications}

To the authors' knowledge, this study was the first to apply the criminal narrative experience framework to previously missing persons. Hence, the findings provide significant support towards the understanding of the differences between the underlying motives of missing persons as well as potential policy implications in relation to the policing and searching of missing persons investigations. The current study further supports advancing research for exploring the criminal experience with a novel and non-crime related approach. The method utilised direct accounts of previously missing persons which allows a much deeper insight into the emotions, experience, and roles exhibited by missing persons as opposed to the majority of research studies which utilise official statistics or secondary data analysis. The use of secondary data analyses fails to offer the richness of the deeper psychological insight that can only be acquired through direct reports made by the missing individuals themselves.

In a practical setting, the use of the missing person narrative experience framework provides the opportunity to aid in the prevention of repeat missing episodes. With the ability to identify and understand the different narrative roles and emotions linked with the specific missing episodes, this would allow organisations and charities involved with supporting 
missing persons to target different interventional approaches accordingly. For instance, understanding a missing child's narrative could be of practical importance during the return home interviews as questions asked, and the overall focus of the interview can be directed accordingly to reflect the narrative. This approach could allow a greater depth of feedback and insight into the missing episode by understanding the way in which the child identifies their own role in their own story and asking questions around this specifically as opposed to generic and standardised questions that are asked to all children during the return home interviews.

Likewise, additional research exploring the link between narrative roles and distances travelled, risk of harm, and locations travelled to during the missing episode would also be of great significance. Financial costs may also be reduced as the utilisation of behavioural themes will assist investigations on prioritising search locations as well as the identification of potential risks of harm. The understanding the missing persons' motivations could help to determine the most likely locations the individuals will travel to whilst missing, although additional research is required to explore this further as this is beyond the scope of the present study.

\section{Limitations and Future Directions}

Whilst the present study provides a novel application of a narrative experience framework to missing persons, there are some limitations which must be considered. The current study analysed data via smallest space analysis which is a sensitive measure based upon the co-occurring relationships between each individual variable with every other variable within the data set. Therefore, adding additional sample data or removing a variable from the analysis for example will likely result in a different SSA geometric plot being produced. Whilst this is a limitation, it can also be argued to be a strength of the measure as whilst individual variables may vary in their position within the geometric plot produced by different analyses of samples and variables, the underlying theoretical basis of the behavioural themes will remain 
and thus may help to continue to establish patterns of relationships of the underlying motives and behaviours of missing persons that subsequently influence their decisions made whilst missing. Likewise, the current analysis was coded by one individual and so inter-rater reliability could not be performed. Instead, intra-rater reliability was performed to explore the consistency of coding over two different time periods to ensure consistency although caution is still required when reviewing the results of the current study analysis.

Moreover, with over 320,000 missing persons reported missing a year in the UK (NCA, 2020), the sample utilised in the current study is exceptionally small. Future research would therefore benefit from exploring the missing person experience framework with a larger and more diverse sample. The data analysed derived from the previously missing persons themselves which does offer a strong psychological insight into their behaviour and emotional experiences, but could not be verified and thus the use of additional materials such as police reports to help verify this information would be beneficial. Finally, the findings may provide the opportunity for future research to develop additional practical measures in the form of an investigative tool that would allow the police to establish potential behavioural themes of missing persons by utilising the initial information that is received by those 'left behind'. The development of an investigative tool would have the potential to increase decision-making processes and decrease the amount of resources, time and finances that would be otherwise involved. 


\section{References}

All-Party Parliamentary Group (APPG). (2016). Inquiry into the safeguarding of 'absent' children: 'It is good when someone cares'. Retrieved from: https://www.childrenssociety.org.uk/sites/default/files/appg-absent-inquiry-finalreport-may-2016.pdf.

Almond, L., \& Canter, D. (2007). Youths who sexually harm: a multivariate model of behaviour. Journal of Sexual Aggression: an international, interdisciplinary forum for research, theory and practice, 13(3), 217-233. doi: 10.1080/13552600701788608.

Alys, L., Massey, K., \& Tong, S. (2013). Investigative decision making: Missing people and sexual offences, crossroads to an uncertain future. Journal of Investigative Psychology and Offender Profiling, 10(2), 140-154. doi: 10.1002/jip.1382.

Biehal, N., Mitchell, F., \& Wade, J. (2003). Lost from view: Missing persons in the UK. Bristol: Policy Press. Retrieved from: http://www.york.ac.uk/inst/spru/research/pdf/lostFromView.pdf

Bonny, E., Almond, L., \& Woolnough, P. (2016). Adult missing persons: Can an investigative framework be generated using behavioural themes? Journal of Investigative Psychology and Offender Profiling, 13(3), 296-312. doi: 10.1002/jip.1459.

Borg, I., \& Lingoes, J. (1987). Multidimensional similarity analysis. New York, NY: SpringerVerlag.

British Psychological Society (2018). Code of ethics and conduct. Leicester: British Psychological Society.

Bruner, J. S. (1990). Acts of meaning. Cambridge, MA: Harvard University Press.

Canter, D. (1994). Criminal Shadows. London: Harper Collins. 
Canter, D., \& Fritzon, K. (1998). Differentiating arsonists: a model of fire setting actions and characteristics. Legal and Criminological Psychology, 3(1), 73-96. doi: 10.1111/j.2044-8333.1998.tb00352.x.

Canter, D., \& Heritage, R. (1990). A multivariate model of sexual offence behaviour: Developments in 'offender profiling'. The Journal of Forensic Psychiatry, 1(2), 185 212. doi: 10.1080/09585189008408469.

Canter, D., \& Ioannou, M. (2004). Criminals' emotional experiences during crimes. International Journal of Forensic Psychology, 1(2), 71-81. Retrieved from: http://www.uow.edu.au/content/groups/public/@web/@health/documents/doc/uow04 5075.pdf.

Canter, D., Ioannou, M., \& Youngs, D. (2009). Safer sex in the city. London: Ashgate

Canter, D., Kaouri, C., \& Ioannou, M. (2003). The facet structure of criminal narratives. In S. Levy \& D. Elizur (Eds.). Facet theory: Towards cumulative social science. Ljubljana, Slovenia: University of Ljubljana, Centre for Educational Development.

Canter, D., Sarangi, S., \& Youngs, D. (2014). Terrorists' personal constructs and their roles: a comparison of the three Islamic terrorists. Legal and Criminological Psychology, 19(1), 160-178. doi: 10.1111/j.2044-8333.2012.02067.x.

Canter, D., \& Youngs, D. (2009). Investigative Psychology: Offender profiling and the analysis of criminal action. Chichester: Wiley.

Canter, D., \& Youngs, D. (2012). Narratives of criminal action and forensic psychology. Legal and Criminological Psychology, 17, 262-272. doi:10.1111/j.2044-8333.2012.02050.x

Frye, N. (1957). Anatomy of criticism: Four essays. Princeton, NJ: Princeton University Press.

Goodlad, K., Ioannou, M., \& Hunter, M. (2019). The criminal narrative experience of psychopathic and personal disordered offenders. International Journal of Offender 
Therapy and Comparative Criminology, 63(4), 523-542. doi: $10.1177 / 0306624 \times 18808433$.

Guttman, L. (1954). A new approach to factor analysis: The radex. In Lazarsfield (Ed.), Mathematical thinking in the social sciences (pp. 258-348). Glencoe, IL: The Free Press.

Hayden, C., \& Shalev-Greene (2016). The blue light social services? Responding to repeat reports to the police of people missing from institutional locations. Policing and Society, 1-17. doi: 10.1080/10439463.2016.1138475.

Henderson, M., Henderson, P., \& Kiernan, C. (2000). Missing persons: Incidences, issues and impacts. Australian Institute of Criminology: Trends and Issues in Crime and Criminal $\begin{array}{llll}\text { Justice, } & 144, & \text { Retrieved } & \text { from: }\end{array}$ http://www.aic.gov.au/media_library/publications.tandi_pdf/tandi144.pdf.

Hirschel, H. J., \& Lab, S. P. (1988). Who is missing? The realities of the missing persons problem. Journal of Criminal Justice, 16(1), 35-45. doi: 10.1016/0047-2352(88)900347.

Hunt, D., Ioannou, M., \& Synnott, J. (2019). Missing Children Photograph Appeals: Does the Number of Appeals Affect Identification Accuracy following a Short Recall Delay? Journal of Police and Criminal Psychology, 34(4), 417-427. doi: 10.1007/s11896-01909337-2

Hunt, D., Ioannou, M., \& Synnott, J. (2020). Effectiveness of Descriptions in Missing Children Appeals: Exploration of Length, Type of Content, and Confidence on Recall Accuracy. Journal of Police and Criminal Psychology, 35(3), 336-347. doi: 10.1007/s11896-01909362-1.

Ioannou, M. (2006). Hero or villain? Criminals' experience of crime (Unpublished doctoral dissertation). University of Liverpool, UK. 
Ioannou, M., Canter, D., Youngs, D., \& Synnott, J. (2015). Offenders' Crime Narratives Across Different Types of Crimes. Journal of Forensic Psychology Practice, 15(5), 383-400. doi: 10.1080/15228932.2015.1065620.

Ioannou, M., Canter, D., \& Youngs, D. (2016). Criminal narrative experience: Relating emotions to offence narrative roles during crime commission. International Journal of Offender Therapy and Comparative Criminology, 61(14), 1531-1553. doi: $10.1177 / 0306624 \times 15625991$.

Ioannou, M., Hammond, L., \& Simpson, O. (2015). A model for differentiating school shooters characteristics. Journal of Criminal Psychology, 5(3), 188-200. doi: 10.1108/jcp-062015-0018.

Ioannou, M., Synnott, J., Lowe, E., \& Tzani-Pepelasi, C. (2018). Applying the criminal narrative experience framework to young offenders. International Journal of Offender Therapy and Comparative Criminology. doi: 10.1177/0306624x18774312.

Ioannou, M., Synnott, J., Reynolds, A., \& Pearson, J. (2018). A comparison of online and offline grooming characteristics: An application of the victim roles model. Computers in Human Behavior, 85, 291-297. doi: 10.1016/j.chb.2018.04.011.

James, M., Anderson, J., \& Putt, J. (2008). Missing persons in Australia. Retrieved from: http://www.aic.gov.au/media_library/publications/tandi_pdf/tandi353.pdf.

Katz, J. (1988). Seductions of crime: moral and sensual attractions in doing evil. New York, USA: Basic Books.

Lingoes, J. (1973). The Guttman-Lingoes non-metric programme series. Ann Arbor, MI: Madhouse Press.

McAdams, D. P. (1988). Power, intimacy, and the life story: Personological inquiries into identity. New York, NY: Guilford Press. 
McAdams, D. P. (2001). The psychology of life stories. Review of General Psychology, 5, 100-122. doi:10.1037/1089-2680.5.2.100

Missing People. (2018). Key information. Retrieved from: https://www.missingpeople.org.uk/about-us/about-the-issue/research/76keyinformation2.html.

National Crime Agency [NCA]. (2017). Missing persons data report 2015/2016. Retrieved from: http://missingpersons.police.uk/en-gb/resources/downloads/download/61.

Payne, M. (1995). Understanding 'going missing': issues for social work and social services. The British Journal of Social Work, 25(3), 333-348. Retrieved from: http://www.jiscjournalarchives.ac.uk.

Presser, L. (2009). The narratives of offenders. Theoretical Criminology, 13(2), 177-200. doi: 10.1177/1362480609102878.

Russell, J. A. (1980). A circumplex model of affect. Journal of Personality and Social Psychology, 39, 1161-1178.

Russell, J. A. (1997). How shall an emotion be called? In R. Plutchik \& H. R. Conte (Eds.), Circumplex models of personality and emotions (pp. 205-220). Washington, DC: American Psychological Association.

Salfati, C. G. (2000). The Nature of Expressiveness and Instrumentality in Homicide: Implications for Offender Profiling. Homicide Studies, 4(3), 265-293. doi:10.1177/1088767900004003004.

Spruin, E., Canter, D., Youngs, D., \& Coulston, B. (2014). Criminal narratives of mentally disordered offenders: An exploratory study. Journal of Forensic Psychology Practice, 14, 438-455. doi:10.1080/15228932.2014.965987 
Santtila, P., Hakkanen, H., Canter, D., \& Elfgren, T. (2003). Classifying homicide offenders and predicting their characteristics from crime scene behaviour. Scandinavian Journal of Psychology, 44(2), 107-118. doi: 10.1111/1467-9450.00328.

Sherman, L. (1998). Evidence based policing. Washington, DC: Police Foundation.

Willmott, D., \& Ioannou, M. (2017). A narrative based model of differentiating rioters. The Howard Journal of Crime and Justice, 1-20. doi: 10.1111/hojo.12194.

Yaneva, M., Ioannou, M., Hammond, L., \& Synnott, J. (2018). Differentiating contract killers: A narrative-based approach. The Howard Journal of Crime and Justice, 57(1), 107123. doi: 10.1111/hojo.12243.

Yokota, K., \& Canter, D. (2004). Burglars' specialisation: Development of a thematic approach in investigative psychology. Behaviormetrika, 31(2), 153-167. doi: 10.2333/bhmk.31.153.

Youngs, D., \& Canter, D. (2012). Narrative roles in criminal action: An integrative framework for differentiating offenders. Legal and Criminological Psychology, 17(2), 233-249. doi: 10.1111/j.2044-8333.2011.02011.x 


\section{Table 1}

Demographic factors of gender, ethnicity, education, employment, marital status, and sexual identity

Demographic Variable

$n$

$\%$

Gender

Male

12

19.70

Female

43

70.50

Other/Unknown

6

9.80

\section{Ethnicity}

White British 30

49.20

White Other

21.30

Black

Asian

4

Other/Unknown

\section{Highest Level of Education Completed}

Primary

Secondary

College/Sixth Form

Trade, Technical or Vocational

Associate Degree

59.00

Bachelors Degree

Masters Degree

1.60

2

1

3.30

Other/Unknown

2

2

3.30

\section{Current Employment Status ${ }^{*}$}

Full Time

\section{6}

9.80

Part Time

19

31.10

Unemployed

9.80

Student

6

40

65.60

Unable

2

Other/Unknown

2

3.30

3.30

Marital Status

Single

Married

Other/Unknown

$\begin{array}{ll}56 & 91.80 \\ 1 & 1.60 \\ 4 & 6.60\end{array}$

\section{Sexual Identity}

Heterosexual

68.90

Bisexual

16.40

Homosexual

10

6.60

Other/Unknown

4

8.10

Note. *The cumulative percentages may be above $100 \%$ due to participants having the option to select more than one response. 
Table 2

Factors associated with the motivation behind deciding to go missing

\begin{tabular}{lll}
\hline Motivational Factor & $n$ & $\%$ \\
\hline Family Problems & 48 & 78.70 \\
Mental Health Problems & 22 & 36.10 \\
Suicide Ideations & 15 & 24.60 \\
Miscommunication & 9 & 14.80 \\
Escape Violence & 8 & 13.10 \\
Relationship Problems & 8 & 13.10 \\
School or Employment Problems & 8 & 13.10 \\
Thrown Out & 7 & 11.50 \\
Financial Problems & 3 & 4.90 \\
Victim of Crime & 3 & 4.90 \\
Escape Arrest & 2 & 3.30 \\
Other & 2 & 3.30 \\
\hline Note. $*$ The cumulative percentages may be above 100\% due to participants having the option \\
to select more than one response
\end{tabular}




\section{Table 3}

Locations visited during missing episode and the outcome of the missing episode

\begin{tabular}{lll}
\hline Motivational Factor & $n$ & $\%$ \\
\hline Location Visited & & \\
Friend Address & 32 & 52.50 \\
Public Park & 28 & 45.90 \\
Family Address & 15 & 24.60 \\
Nearby Town or City Location & 15 & 24.60 \\
Countryside & 11 & 18.00 \\
Shopping Centre or High Street & 10 & 16.40 \\
Abandoned or Empty House & 8 & 13.10 \\
Bedsit, Hostel or Hotel & 7 & 11.50 \\
Other Location & 5 & 8.20 \\
Hospital & 4 & 6.60 \\
Partner Address & 2 & 3.30 \\
Missing Episode Outcome & & \\
Returned on own Accord & 36 & 59.00 \\
Found by Police & 9 & 14.80 \\
Found by Family & 7 & 11.50 \\
Found by Friend & 6 & 9.80 \\
Found by Other & 4 & 6.60 \\
Found by Someone Else & 2 & 3.30 \\
\hline
\end{tabular}

Note. *The cumulative percentages may be above $100 \%$ due to participants having the option to select more than one response 


\section{Figure 1 Caption:}

Figure 1. Smallest space analysis of the distribution of the 62 statements.

Note: Guttman-Lingoes coefficient of alienation $=0.147$. 